\title{
LA EVOLUCIÓN DEL URBANISMO DE ÉCIJA (SEVILLA) DE LA TARDOANTIGÜEDAD A LA ÉPOCA ISLÁMICA
}

\author{
DANIEL BECERRA FERNÁNDEZ \\ UNIVERSIDAD DE SEVILLA \\ danbecfer@hotmail.com
}

Diego Blancat Castilla

UNIVERSIDAD DE SEVILLA

blancat13@hotmail.com

Sergio Almisas Cruz

UNIVERSIDAD DE SEVILLA

\section{RESUMEN}

Con este artículo pretendemos abordar los aspectos generales del transito entre la Antigüedad tardía y la Alta Edad Media en la ciudad de Écija, abordando sus aspectos más significativos y analizando su evolución desde su configuración como ciudad romana, hasta su transformación en una ciudad andalusí.

Palabras Clave: Écija, Maqbara, andalusí, Astigi, Istiyya, islamic.

\section{AbSTRACT}

With this article we address the general aspects of the transition between late antiquity and the early Middle Ages in the city of Ecija, addressing its most significant aspects and analyze its evolution since its configuration as a Roman city until its transformation into an Islamic city.

KEYwoRDS: Écija, Maqbara, andalusí, Astigi, Istiyya, islamic.

Sin duda alguna, uno de los periodos históricos más vacíos en cuanto a información se refiere de la ciudad de Écija es la época medieval andalusí. Esta ausencia de información es fruto de la escasez hasta el momento de estudios en profundidad, hecho que muestra sus secuelas en el aspecto urbanístico en el cual nos centramos en este trabajo. Esta situación hace que cualquier estudio sobre la Écija medieval andalusí deba partir de los datos pertenecientes al mundo visigodo y tardoantiguo, heredero de la actividad desarrollada por Roma en esta ciudad, para observar la evolución acontecida hasta la conquista cristiana en el año 1240.

Intentaremos desarrollar en el trabajo los aspectos urbanísticos y sociales de Écija, principalmente, y tangencialmente su territorio, en el tránsito a la Edad Media centrándonos en el mundo andalusí, en la formación de la Istiyya islámica que será la que conocerá el mundo cristiano a mediados del siglo XIII. 
Para esto, analizaremos diversos aspectos de la ciudad, desde su propia evolución urbanística, de sistemas defensivos, pasando por las necrópolis, hasta la evolución político-social de la ciudad insertada en su territorio.

\section{Sociedad astigitana en el tránsito de la época tardoantigua a la musulmana.}

Comprender la evolución poblacional y económica de la ciudad y su ámbito de dominio o relación, es básico para entender las dinámicas que se producen en la ciudad en cuanto a su morfología urbana. Así pues, pasaremos ahora a tratar este asunto.

Como en el caso de las murallas, para entender la génesis social islámica Écija, es necesario que partamos de un conocimiento de la sociedad y economía tardorromanas que serán las que generen, junto con los aportes poblacionales, civilizatorios y políticos de los árabes y bereberes, la sociedad andalusí astigitana.

La Bética vive en época bajoimperial un proceso de crisis del estado romano que, a la par del resto del Imperio, supone un fortalecimiento de las aristocracias terratenientes o posesores, así como una polarización en la tenencia de la tierra y un descenso de circuitos comerciales. Todo esto se une a las crisis monetarias, ya desde el siglo III, a la pérdida de importancia de la burocracia imperial y la inestabilidad en los siglos IV-V, que va creando una situación socio-económica nueva que señalará el fin del Imperio Romano (Duran y Padilla 1990: 122-128).

En Écija, el proceso de cambio que conduce a la sociedad tardoantigua parte de la importante situación de la civitas durante el periodo imperial. Se trataba de un gran centro agrícola y comercial, capital de un conventus iuridicus y la ciudad más importante de la Bética en época romana y tardoantigua junto con Hispalis y Corduba (Duran y Padilla 1990: 91). En su territorio, se fueron desarrollando en estos siglos de dominación romana las villae o explotaciones agrícolas familiares que, lejos de estar aislados de la ciudad, formaban una realidad política y social unitaria la civitas, res publica o urbs. Estos asentamientos o villae, a pesar de la crisis de fines del siglo III, tendrán continuidad desde el siglo II al IV (Duran y Padilla 1990: 21-22). Los possesores o terratenientes se harán más fuertes y se convertirán en una clase social más restringida, aprovechando la ruina de pequeños y medianos propietarios por las altas cargas impositivas y el final de las transacciones comerciales. De hecho, en el siglo IV dejamos de encontrar en el registro arqueológico villae nuevas como venía ocurriendo en los siglos anteriores. Este panorama podemos completarlo con la comprensión de la ciudad, Astigi, que será controlada por la élite rentista; élite que, una vez se derrumbe definitivamente la superestructura imperial, serán los rectores de la sociedad (Duran y Padilla 1990: 127-128). La ciudad pasa ahora (siglos IV-V) a convertirse un espacio controlado por estos nobles, como marco de prestigio social, pero vaciado de su función de comercio y de aglomeración de sectores gubernamentales. La población se aglomera en las diferentes dependencias rurales como trabajadores dependientes de estos señores (Durán y Padilla 1990: 128-129). Hay que contar como desde el siglo IV debería tener estatuto episcopal a la vista de su categoría urbana y de la presencia de sus obispos en los concilios de Toledo de 589 y de Sevilla de 590. Dicha sede episcopal está atestiguada hasta el siglo X, momento en el que desaparecen los testimonios al respecto a la par de la progresiva desaparición de las comunidades mozárabes en la región.

Para el periodo visigodo tenemos una situación heredada del periodo tardorromano, en el que en la zona de Écija se mantienen las estructuras más arriba analizadas, debido a que el poder visigodo se sentiría poco en el sur peninsular. De este modo, continuaríamos con el proceso de encomendación de una gran parte de la población libre a los señores hispano-romanos y a un pequeño número de nobles visigodos que llegarían desde el norte, creando una gran capa de campesinos dependientes y 
libertas, siervos y simi-libres (Bendala 1980:174-176). Así mismo, el proceso de autarquía y pérdida de contactos comerciales con, por ejemplo, el norte de África ${ }^{1}$, se iría agudizando en un proceso que terminará con la entrada de poblaciones musulmanas y norte africanas en lo que se ha venido llamando Conquista Musulmana (Duran y Padilla 1990: 21-22). Otros autores han señalado como resultado de este proceso un vacío poblacional de la ciudad a partir de los siglos IV-V, mientras sus élites permanecerían asociadas a la sede episcopal (Rodríguez 1993: 374-375). Sin embargo, hay que decir que para este periodo tenemos pocos datos de la población y de la estructura de la sociedad y de sus ciudades, tanto de tipo arqueológico como documental-escritas.

La entrada de las tropas musulmanas en la ciudad de Écija se produce en el año 711 al mando de Tariq ibn Ziyâd, quien de camino hacia Córdoba, procedió al asalto de las murallas de la ciudad. Al contrario de lo acontecido en Sevilla, donde la población pactó con las tropas asaltantes su rendición de forma pacífica, en Écija se documenta una fuerte oposición al ejército islámico, lo que marcará en cierto modo su historia.

En lo que respecta a la sociedad andalusí que nace en los siglos VIII y IX, podemos empezar por la llegada de las tropas árabes y norteafricanas a la península, fruto de la debilidad del estado visigodo y sus pugnas por el poder con los nobles terratenientes. En los primeros años habría una situación general de continuidad entre el mundo visigótico el naciente mundo andalusí, debido a que la entrada de los árabes fueron por medio de capitulaciones. De esta manera, se crearon lazos o dependencias fiscales ya que dichas capitulaciones requerían de un pago de un impuesto (Sánchez 1980: 194-198). Los siglos VIII y IX serían de consolidación de la dominación árabe, con el problema inicial de los repartos de tierra entre árabes y bereberes, los conflictos con la población local (de la que sabemos poco en estos años), la llegada de los sirios al mando de Baly que complicará las tensiones sociales, etc. (Sánchez 1980: 199). En estos siglos vemos el paso a una sociedad que empieza a demandar trabajos artesanos y comerciantes de mano de unas élites árabes o de la corte emiral cordobesa, dando a paso al resurgimiento del urbanismo (Sánchez 1980: 229-231). En el siglo IX ya se empieza a consolidar el estado Omeya, con represión de la disidencia, aumento de la fiscalización, islamización ${ }^{2}$, etc. que causa una urbanización renovada en este siglo (Sánchez 1980: 233-235). Hay que remarcar que el carácter urbano de esta nueva civilización tiene una raíces clásicas, en tanto que sólo las zonas romanizadas estarían bajo el control del nuevo estado (Domínguez y Cervera 2005: 191-192). En lo que respecta al mundo rural andalusí, debemos apuntar que este sistema estatal tributario se basa en la erradicación de las tendencias feudalizantes en la que la posibilidad de existencia de señores recaudadores de rentas sea imposible. Podemos observar una separación entre el estado y la organización territorial de los productores, en base a un modelo clánico agrícola nucleado por alquerías (Domínguez y Cervera 2005: 192). Por su parte, las revueltas de muladíes (hispano-visigodos convertidos al Islam) ha puesto de manifiesto la posible falta de cohesión de la sociedad andalusí a fines del siglo IX (Sánchez 1980: 244-248), que estaría motivada por un choque de estructuras socio-económicas entre las de tipo segmentada, tribal o clánica del aporte alógeno y la tendencia feudal de los autóctonos, sobre las que se situaría y controlaría el estado califal omeya (Viguera 1994: 21). Este hecho resulta especialmente interesante para analizar la estructura social de Écija en la Alta Edad Media.

1.- Habría que indicar la posible revitalización del comercio en Andalucía Oriental debido a la llegada de los bizantinos en estos años tardorromanos y visigodos.

2.- En este proceso de islamización y arabización también entrarían en juego la población bereber (Viguera 1994: 20-22).

3.- En este contexto territorial, las ciudades se entienden más como foco de presencia sultánica que como núcleos poblacionales, excepto ciertas capitales regionales (Domínguez y Cervera 2005: 193). 
En la cora de Écija, podemos aseverar que, tras la caída del sistema romano, tiene un comportamiento en sintonía con el proceso de estatalización del área nuclear andalusí por parte del califato (Domínguez y Cervera 2005: 191-192). Sin embargo, podemos señalar la continuidad de la importancia del territorio, como herencia romana (Valencia 1988: 317-318), que va de la mano de su gran productividad agrícola que, como en el mundo antiguo, la convirtió en zona neurálgica de la bética. Se trata de una cora muy amplia, dividida en aqálim o distritos rurales de los que no se conoce casi nada (Borrero 2005: 293).

Antes de iniciar el análisis del poblamiento urbano y rural de la qora de Istiyya, debemos apuntar que las fuentes documentales nos hablan poco de esta comarca (Domínguez y Cervera 2005: 193-194, Borrero 2005: 293, Valencia 1988: 315-316), teniendo que utilizar la literatura geográfica o Libros de Viajes cuya información no es muy objetiva y tratan este ámbito rural de forma marginal ya que se centraron en las ciudades (Borrero 2005: 293 y Valencia 1988: 315-316). Esta escasez de datos, sin embargo, no es destacada por Rafael Valencia (1988: 315), quien apunta más a la falta de investigaciones centradas en la Écija altomedieval. Por su parte, el registro arqueológico, tanto del mundo urbano como rural, es deficiente, en el primer caso por la visión monumental de la arqueología que relegaba el registro arqueológico andalusí a un segundo plano (como parasitario del romano) (Domínguez y Cervera 2005: 203- 204), y en el segundo debido al marco metodológico de la arqueología del paisaje y territorial, que encuentra dificultades para detectar yacimientos (tanto por la degradación de los mismos como por el propio método) y, además, se inflan el número de estos por la asignación de escasos restos cerámicos a unidades poblacionales como alquerías (Domínguez y Cervera 2005: 199-200).

En el ámbito territorial, vemos como se han documentado arqueológicamente diferentes modelos de poblamiento rural y urbano de los que podemos encontrar una sistematización, aunque altamente formal y sin abundar en aspectos sociales y de cambio histórico, en Vargas et alii (1993), donde señalan una jerarquización del poblamiento en ciudades amuralladas o medina, otros dispositivos defensivos; y núcleos rurales de primer, segundo y tercer orden. Podemos, sin embargo, sintetizar el territorio de la cora de Istiyya como una campiña donde encontramos unos enclaves principales enmarcados por un fértil territorio agrícola en torno al río Guadalquivir y sus afluentes (Genil, Corbones y Guadaíra). Esta comarca esta articulada por caminos históricos como los que une Sevilla con Córdoba y con Antequera, así como caminos secundarios norte-sur (Domínguez y Cervera 2005: 190). En lo que respecta al poblamiento rural, vemos cómo las alquerías o asentamientos rurales se asocian a la red viaria secundaria (más que a la principal) y en torno a la red hidráulica (río Genil y Arroyo Salado), disponiendo un territorio centrado en las alquerías (que capitalizan los testimonios numismáticos evidenciando los flujos económicos con el estado tributario). El sistema de cultivo de regadío, como veremos en el punto económico, estaría extendido, algo recogido en parte en las fuentes árabes (Domínguez y Cervera 2005: 209-211). Por su parte, los pocos núcleos urbanos, que conocieron como época de desarrollo el periodo de estabilidad del califato (s. IX), no pudieron desarrollarse completamente debido a las tensiones y conflictos territoriales en los siglos XI-XIII, en un contexto en el que serían considerables las tendencias de despoblamiento (quizás con los almohades sí se inician tareas de colonización importantes) (Domínguez y Cervera 2005: 194-195).

Un punto aparte en el estudio territorial se merece la madina. Ecija es la capital de la cora (distrito de carácter civil, judicial, religioso, fiscal y militar) homónima, convirtiéndose en centro de comunicaciones, focalizando la red viaria y el territorio agrícola (además de otros centros como Osuna o Marchena) (Valencia 1988: 317-322). Será así que la ciudad alcanza un gran potencial económico como muestran las relaciones que entablan personajes astigitanos con el poder andalusí omeya o abbasí (Valencia 1988: 325). La población, aunque no alcanzase la enorme cifra que indicaba Levi-Provençal, 
sería considerable dado el esplendor de la cora y de sus élites, algo que, sin embargo, no están de acuerdo todos los investigadores ${ }^{4}$ (Valencia, 1988: 327). El análisis formal de la misma se ofrece en otro apartado del trabajo.

Desde el punto de vista social, en la élite social nos encontramos con una base hispanovisigoda a la que se acopló una minoría árabe, a cuyos linajes se fueron uniendo como clientes los hispano-visigodos (Valencia 1988: 327). Los mozárabes, que serían importantes, tendrían su imagen más visible en la jerarquía eclesiástica (Valencia, 1988: 327-328). A su vez, el vínculo de clientela con las familias árabes también lo hacen los bereberes que llegan a la península y que son especialmente numerosos en Marchena y Osuna (Valencia 1988: 329). Con respecto a la conversión al Islam, Valencia ha apuntado (1988: 329) que se haría debido a las ventajas económicas y sociales y al relativo poco esfuerzo personal que debía suponer el paso a una religión también monoteísta, simples y con grandes influencias cristianas.

En lo que se refiere a la economía que encontramos en Écija en época andalusí, tenemos elementos básicos de continuidad con respecto a la Astigi romana. Por un lado, la producción básica del área rural ecijana fue la cerealística (trigio, cebada o sorgo), dedicada a su molienda para la panificación a través de aceñas o molinos hidráulicos que se documentan en la ribera del Genil. Para la regulación de esta producción, AlHimyari nos habla de la existencia de mercados alrededor de la alhóndiga de Écija. La posición de Écija entre las dos grandes capitales andalusíes hizo que, además de cubrir un mercado local y regional, se abasteciera a los mercados de Sevilla y Córdoba (Borrero 2005: 293-295). Esta actividad estaría atestiguada en la antroponimia, al hablar de nombres familiares como Al-Barraz ("comerciante de granos") (Valencia 1988: 322). Por otro lado, tenemos la existencia, no documentada, de olivares y campos de vides que tendrían mercados asociados; y de los cultivos de regadío, debido a la extensión de los sistemas de irrigación y las norias y acequias (Valencia 1988: 318). El resultado de esta economía es fruto de la herencia romana sobre la que se impulsan unos sistemas agrícolas muy productivos (varias cosechas al año), viviendo una floreciente etapa en la que consigue insertarse en los circuitos comerciales de Al-Andalus y crecer su población (Borrero 2005: 293-295).

\section{INTRODUCCIÓN AL URBANISMO}

Respecto al urbanismo precedente en la ciudad a la llegada de las tropas musulmanas, éste es heredero del de época romana y visigoda, siendo el elemento más característico la muralla, la cual será descrita más adelante.

Sobre la morfología urbanística de la Écija en los siglos anteriores a la llegada de los musulmanes apenas conocemos sino hallazgos aislados que no permiten por ahora hacerse una idea ni de su extensión ni de sus edificios más representativos.

Resulta evidente que ya por entonces comenzó a restringirse el perímetro de la ciudad, quedando así zonas despobladas intramuros, y que, probablemente por la pérdida de su funcionalidad, los grandes edificios públicos fueron desmantelados y sus materiales reaprovechados en otras construcciones. Muestra de ellos son por ejemplo las estructuras de la Plaza de España y la zona forense de Miguel de Cervantes, Emilio Cautelar y Mármoles, sobre las que surgen por entonces viviendas de escasa entidad.

4.- cfr. M.L. Avila (La sociedad hispanomusulmana al final del califato. Madrid 1985, pp. 80 s.), la reducción de la ciudad se debería a una profunda crisis poblacional que vive la madina en toda la presencia árabe (citado en Rodríguez 1993: 374-375). 
Otro aspecto a resaltar en cuanto a la trasformación que sufre la ciudad es el desplome de muros y estructuras sobre la vía pública sin que se tomen medidas para evitarlo, generándose así niveles de escombros indicativos de la descomposición y pérdida de vigor de la normativa que afectaba a estos espacios públicos. Con estas premisas, la trama del viario hipodámico de época altoimperial comienza a descomponerse e inicia su transformación hacia fórmulas propiamente medievales, mientras la red de alcantarillado debió de sufrir también este proceso traducido en colmataciones, ausencia de reparaciones, desplomes..., que llevarían a la pérdida de su funcionalidad.

\section{Descripción MORfológica y uRBANística de la ÉCIJA ANDAlusí}

La ciudad propiamente islámica se estructurará sobre las bases del mundo romano y tardoantiguo preexistentes. Al igual que ocurriera en el anterior periodo, muchas zonas urbanas serán el objetivo de actividades de acarreo para el mantenimiento de otras estructuras o la construcción de edificios de nueva planta. Así podemos mencionar la existencia de numerosos pozos y zanjas de saqueo destinados a obtener materiales de viviendas sepultadas o en estado ruinoso. Un ejemplo de ello lo encontramos en la intervención arqueológica preventiva realizada en el número 15 de la Plaza de Puerta Cerrada (Cilla del Cabildo). En dicha intervención se documenta, respecto al periodo islámico, una actividad de expolio de las estructuras tanto de manera superficial como mediante la realización de zanjas y pozos de saqueo. Contemporáneamente, los pozos de saqueo van a ser utilizados como muladares al menos desde el siglo X. Durante el periodo almohade se produce la fase final del expolio de las estructuras romanas, como consecuencia quizás de la necesidad de reunir materiales de acarreo para la construcción de la muralla de la ciudad (García 2004). Debemos mencionar que en éste caso la zona exhumada se situaría en un sector de la ciudad que presenta una clara tendencia al abandono, al menos de forma parcial, desde época tardorromana y quedaría fuera del recinto amurallado de época almohade.

Respecto al ámbito de viviendas conocidas en el interior de la madina, éstas constituyen hoy en día un número insuficiente y se hallan excavadas en poca extensión, hecho que nos impide establecer hipótesis acerca del desarrollo de la trama urbana de Écija a lo largo de periodo islámico. Si poseemos constancia arqueológica de cuatro viviendas o estructuras relacionadas con dicha función las cuales serán descritas a continuación.

Una de ellas, la más septentrional, se ubica en Merinos c. v. Puerta Nueva c. v. Jurado, colindante con el lienzo de la muralla. Durante la intervención arqueológica se detectó un muro en emplecton con cara de ladrillos y relleno de mampuestos de piedra y tegulae, de orientación N-S, perteneciente a una vivienda de época almohade (Muñoz 1997). Ya en plena madina ubicamos una en Barrera de Oñate s. n. tipificada como casa islámica (Carrasco 1991), mientras en Miguel de Cervantes 3, se exhuman restos estructurales de una vivienda denominada como islámica, fechada entre los siglos IXXI, construida sobre el enlosado del Foro de época augustea y donde se hallo material cerámico variado (Rodríguez 1988). Por último en Miguel de Cervantes c. v. a Mármoles se excava una posible casa islámica construida sobre un conjunto estructural perteneciente a restos constructivos bajoimperiales sobre el foro romano de la ciudad. Se detecta un pozo ciego islámico además de un nivel de relleno de misma época y un repertorio cerámico compuesto piezas de utilidad doméstica. (Cruz 1998).

Las dos primeras viviendas se relacionan con sendos adarves, lo que indica la descomposición de la trama romana y su sustitución por un entramado urbano en el que los criterios de ordenación están dominados por la privacidad (Rodríguez 1993).

En cuanto a infraestructuras hidráulicas en esta época, la información que poseemos proviene de dos inscripciones cúficas ubicadas actualmente en la torre de la iglesia de Santa Cruz. Dichas inscrip- 


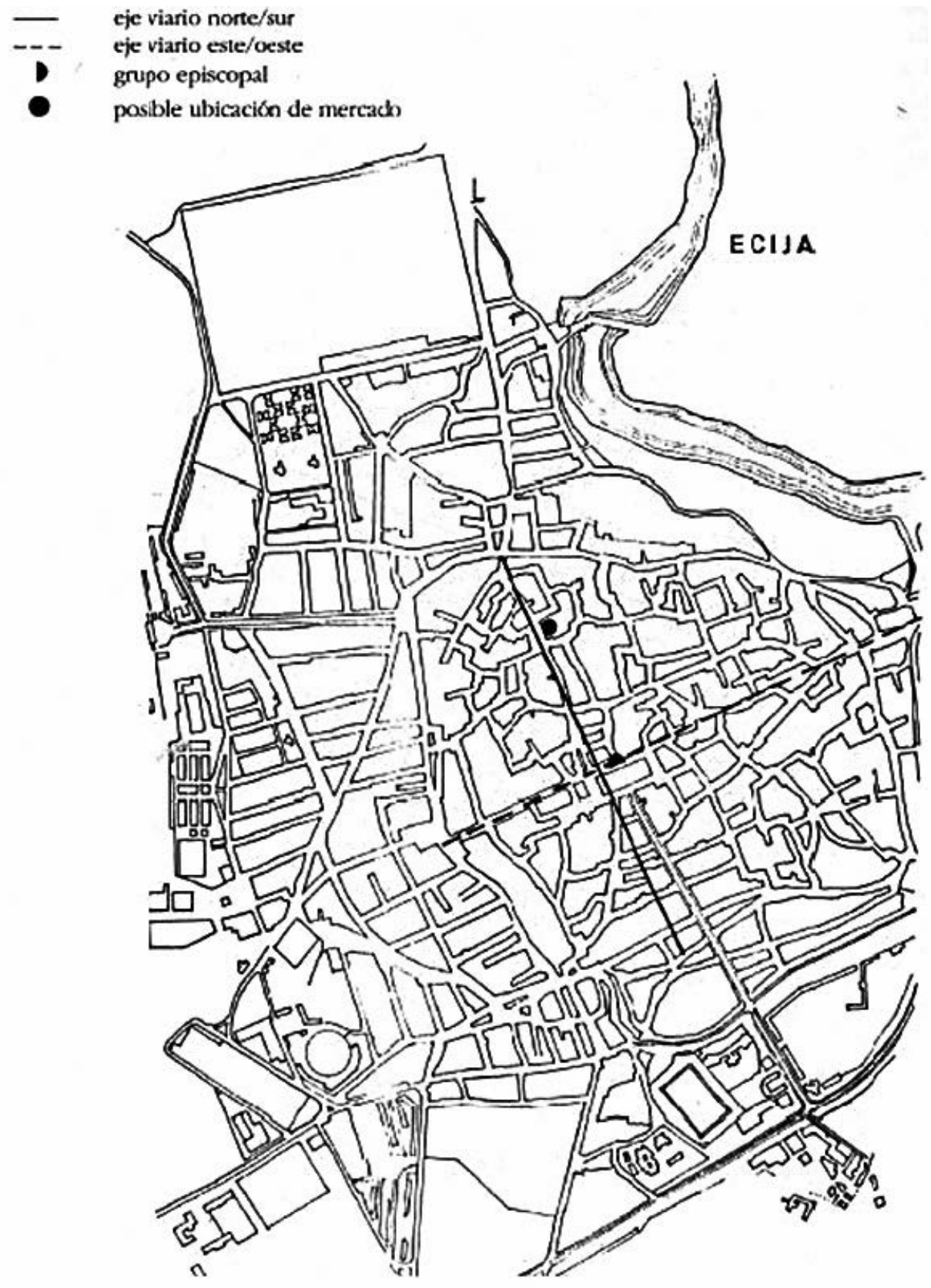

Figura 1.Eje de la ciudad en época visigótica, con los dos posibles centros de la ciudad el mercado y el grupo episcopal (Rodríguez 1993:380) 
ciones mencionan la existencia de fuentes de las que no es posible conocer su ubicación actualmente. El texto correspondiente a cada una de ellas, en la transcripción de Levi-Provençal, dice así:

“... ha ordenado el Emir de los creyentes -que Allah lo ilustre- Abd-ar Rahman hijo de Muhammad la construcción de esta fuente con la esperanza de una hermosa recompensa de Allah (y de una magnífica retribución) y este (trabajo) se terminó con la ayuda de Allah bajo la dirección de su liberto y de su gobernador Umaiya, hijo de Muhammad ibn Usaid en el mes de Al-Muharram del año 318. Corresponde, pues, a febrero del año 930, realizándose la construcción por mandato del califa Abd alRahmán II."

El segundo de estos textos muestra la actuación edilicia de Subh, la favorita de AlHakam II y madre del califa Hixám II, reinante en el momento de la dedicación (noviembre-diciembre de 977):

“... ha ordenado la construcción de esta fuente la señora-que Allah la ilustre- la valida, la madre del Emir de los creyentes Al Mu aiyad billah Hisam hijo de Al-Hakam -qué Allah prolongue su vida- con la esperanza de una hermosa recompensa de Allah y de una magnifica retribución, y (esta fuente) se terminó con la ayuda de Allah y su asistencia bajo la dirección de su protegido el jefe de policía y kadíde la población del distrito de Écija, Carmona y dependencias, Ahmad hijo de Abdallah, hijo de Musa y esto en el mes de rabi II del año 367."

Al margen de estos testimonios, se ha de mencionar que la red de abastecimiento de agua y el drenaje de aguas residuales en los edificios de uso privado es prácticamente inexistente, hecho demostrado por el gran número de pozos ciegos pertenecientes a época andalusí y que a su vez confirma el proceso de desintegración de los servicios públicos de época romana.

En varias ocasiones se ha recuperado durante las distintas intervenciones arqueológicas restos de piletas islámicas realizadas con materiales romanos reutilizados (Muñoz 1997), mientras que la detección de restos de arcaduces apuntan a la posible existencia de norias que además se situarían en torno al foso que rodea la muralla, aprovechando así el caudal del arrollo que circulaba por él hasta
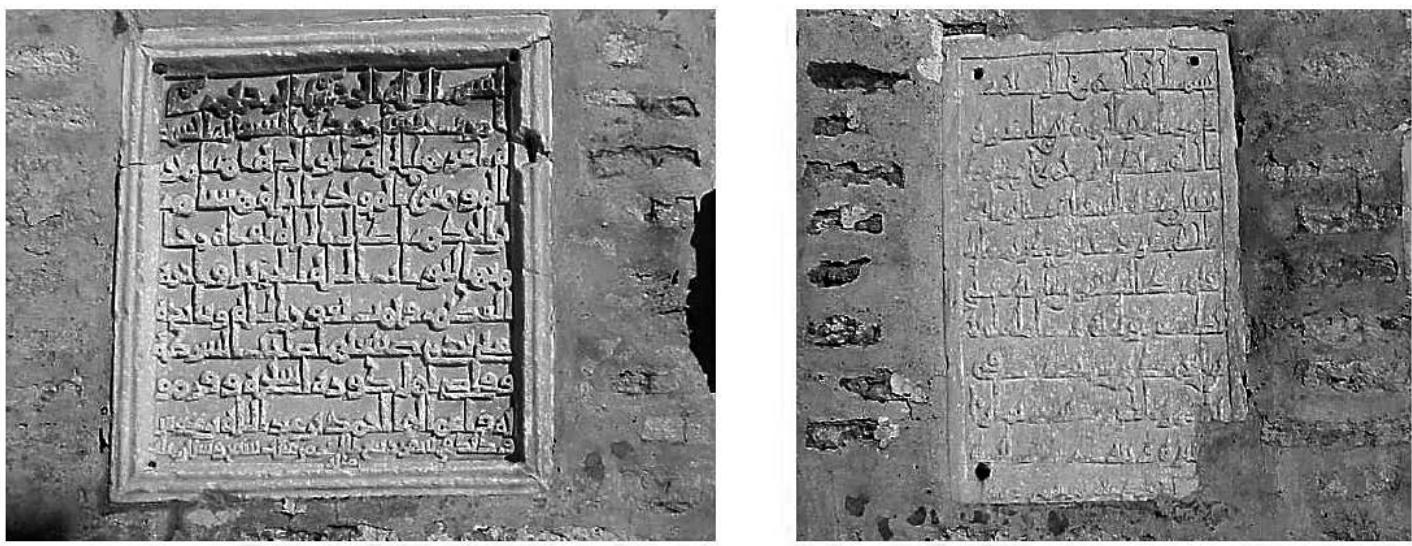

Inscripción de Abderrahman III e inscripción de Subh

llegar al río Genil.

En el texto del Repartimiento de época cristiana se nos transmite la referencia a la existencia, a los pocos años de la conquista, de algunos establecimientos termales que han de considerarse como baños islámicos. Este es el caso de los denominados Baños del Rey y el Horno de las Aguas, ambos ubi- 
cados en la collación de San Juan. Finalmente se ha de señalar la posible existencia de unos baños que la tradición ubica en la calle Celestino Montero, antigua calle Baños, quizás identificable en el mismo texto del Repartimiento con una cal del banno viejo.

Por lo que concierte a las áreas de mercado, las fuentes literarias mencionan en alguna ocasión zocos en la madina, de localización imprecisa ${ }^{5}$. Es el caso del zoco que, según estas fuentes, debía de estar situado en las inmediaciones de la Báb al-Suwaíqa, la Puerta de Palma, según Al Himyarf 6 .

En cuanto al ámbito artesanal, se ha mencionado la presencia de alfares islámicos en diversos puntos de la ciudad, tanto intramuros como extramuros. Es el caso de Cristo de Confalón s/n. donde se ha postulado la existencia de un alfar construido sobre el solar de una villa suburbana de época tardoimperial y de la necrópolis romana situada en las inmediaciones. En esta excavación se halló además un conjunto de atifles y cerámica vidriada (Núñez y Rodríguez 1987). En otros lugares el registro estratigráfico y la presencia de desechos de alfar permite teorizar sobre la presencia de establecimientos artesanales destinados a la elaboración de recipientes de variada tipología. Si bien, todos estos establecimientos se encuentran extramuros con la única excepción del hallado en José Canalejas c. v. Trascampanario, donde se localiza un alfar intramuros aunque anexo prácticamente a la cerca (Núñez y Huecas 1990).

Finalmente, entre los elementos urbanísticos públicos debemos mencionar el puente sobre el río Genil, frecuentemente citado en las fuentes en relación con acontecimientos bélicos y riadas, y del que se postula tradicionalmente un origen romano de cuya labor no queda hoy nada constatable. AlIdrïsï sostiene que se trata de un puente de sillería, si bien hoy día su fábrica es de ladrillo, lo que ha llevado a asignarle una cronología situada entre los siglos XII y XV (Valencia 1988: 324, Pavón 1990: 149).

\section{MUNDO FUNERARIO Y RELIGIOSO}

Por lo que afecta al ámbito funerario, uno de los aspectos más relevantes de la documentación arqueológica referida a época islámica en Écija es la existencia de cementerios en el interior de la madina. Este caso se corresponde con el exhumado en la Plaza de España, fechado entre los siglos IX y XIII cuya duración en el tiempo y extensión parece suficiente para cuestionar la exclusividad en las ciudades islámicas del modelo de cementerios extramuros ${ }^{7}$. Esta maqbara puede ponerse en relación con unos baños mencionados por Roa (c/ Celestino Montero) y una alhóndiga que los excavadores de la Plaza de España (Vargas y Romo 1998: 68) ubican según informaciones documentales en la zona situada inmediatamente al oeste de la iglesia de San Francisco, lo cual hace posible deducir que estamos ante una de las denominadas unidades funcionales que se articulan en torno a una mezquita ofreciendo diferentes servicios (fundaciones piadosas) administrados por ésta.

5.- Valencia (1988: 318 y 322): Al-Idrísi se refiere a los importantes mercados de la ciudad, mientras que otras fuentes destacan el importante papel de su actividad comercial.

6.- Levi-Provençal (1938: 15 Y 21). Valencia (1988: 323). Rodríguez (1993: 378). Sitúa este zoco como el principal de la ciudad, ubicándolo en la manzana creada por las calles Santa Florentina, José Canalejas y Santa Catalina, por la especial configuración del urbanismo de esa área, así como por la permanencia de un área de mercado en esta zona en la primera mitad del siglo XIV

7.- Ejemplos como los de las makbaras intramuros de Almería, Murcia o Valencia, constituyen adecuados paralelos para el gran cementerio astigitano (Navarro y Jiménez 2003). 
Dicha mezquita, según los autores del informe de las excavaciones de 1998 en "El Salón", de la que dependían estas instituciones piadosas reconocidas como cementerio, alhóndiga y baños o posible mida, no sería sino la aljama edificada en piedra, con cinco naves y columnas de mármol citada por Al-Himyari, que pudo encontrarse en el solar de la iglesia del convento de San Francisco o bien en su parte trasera, en las Carnicerías reales, siendo éste además el punto a partir del cual se realiza el repartimiento de la villa ${ }^{8}$. Se contradice así la hipótesis tradicional formulada originalmente por Varela y Escobar, que sitúa la mezquita mayor en la iglesia de Santa Cruz, sede del episcopado visigodo. Aún así, serán las excavaciones futuras las que permitan confirmar o desestimar una u otra hipótesis, aunque sí parece claro que la hipótesis de los excavadores de El Salón permite articular de forma coherente el centro urbano de la Écija islámica.

En cualquier caso, lo cierto es que la consagración de la mezquita aljama debió hacerse al comienzo de la dominación islámica, a tenor de lo expresado por Ibn Hayyân cuando afirma que bajo el emir Muhammad (852-886) se hubo de restaurar esta edificación.

La ausencia de noticias respecto a otras mezquitas $u$ oratorios puede justificarse por el relativamente pequeño tamaño de la ciudad en época andalusí, aunque la presencia de enterramientos intramuros en Mármoles, 6 y Mármoles c. v. Miguel de Cervantes (Carrasco y Romero 1993) combinada con la cercanía de unos posibles baños en la zona de la puerta de Estepa y de otros probables en la actual calle Bañales, pueden hacer suponer sobre la existencia de otra de estas áreas funcionales dependientes de una mezquita secundaria, cuestión que se ha de confirmar o negar en futuras excavaciones.

Estos enterramientos intramuros no implican aún así la inexistencia de necrópolis fuera del recinto amurallado de la ciudad tal y como se documentan en la Plaza de Giles y Rubio s. n. y 19 (Carrasco 1995) y Puerta Cerrada c. v. San Juan Bosco (Núñez y Rodríguez 1984). Este hecho supone que, a pesar de la existencia de terrenos no ocupados en el interior de la ciudad ${ }^{9}$, se siguieron usando las áreas extramuros dedicadas a enterramientos, o, al menos, parte de ellas, hasta momentos mudéjares.

En lo que respecta a la maqbara exhumada en las excavaciones realizadas en Plaza de España, ésta será descrita en el apartado siguiente.

\section{La Maqbara de El Salón}

A partir del siglo I d.C. se documenta en lo que hoy se corresponde con la Plaza de España, o también conocido como El Salón, un conjunto habitacional correspondiente a una serie de insulae vertebradas en torno a uno de los kardo de la colonia romana. Anexo a la parte este de esta zona se documentó un espacio cercado que enmarca el temenos, un recinto de culto donde se ha detectado el pódium de un templo y un estanque destinado a fines litúrgicos (García-Dils 2009).

Sobre este espacio, ya adentrados en el siglo $\mathrm{V}$, se detecta a raíz de las excavaciones arqueológicas una serie de tumbas asociadas quizás a una basílica de tres naves (García-Dils 2005), lo que ya transfiere la idea de la función que adquirirá este espacio siglos después. Se trata de enterramientos de inhumación cuyas tumbas son muy homogéneas y reutilizan muchos elementos del periodo romano, presumiblemente de las viviendas aledañas y del espacio forense ya abandonado.

8.- El repartimiento se hace concretamente a partir de la mezquita de la bodega de don Nuño del termino de la carnicería, allí donde se parten las tres collaçiones sancta cruz e sancta maria e sancta barbara , y desde cuya torre se examinó la ciudad para proceder a la división (Sanz 1976). La referencia a la Carnicería permite ubicar este establecimiento primitivo no muy lejos de donde en el siglo XVI se elevarían las Carnicerías Reales. 

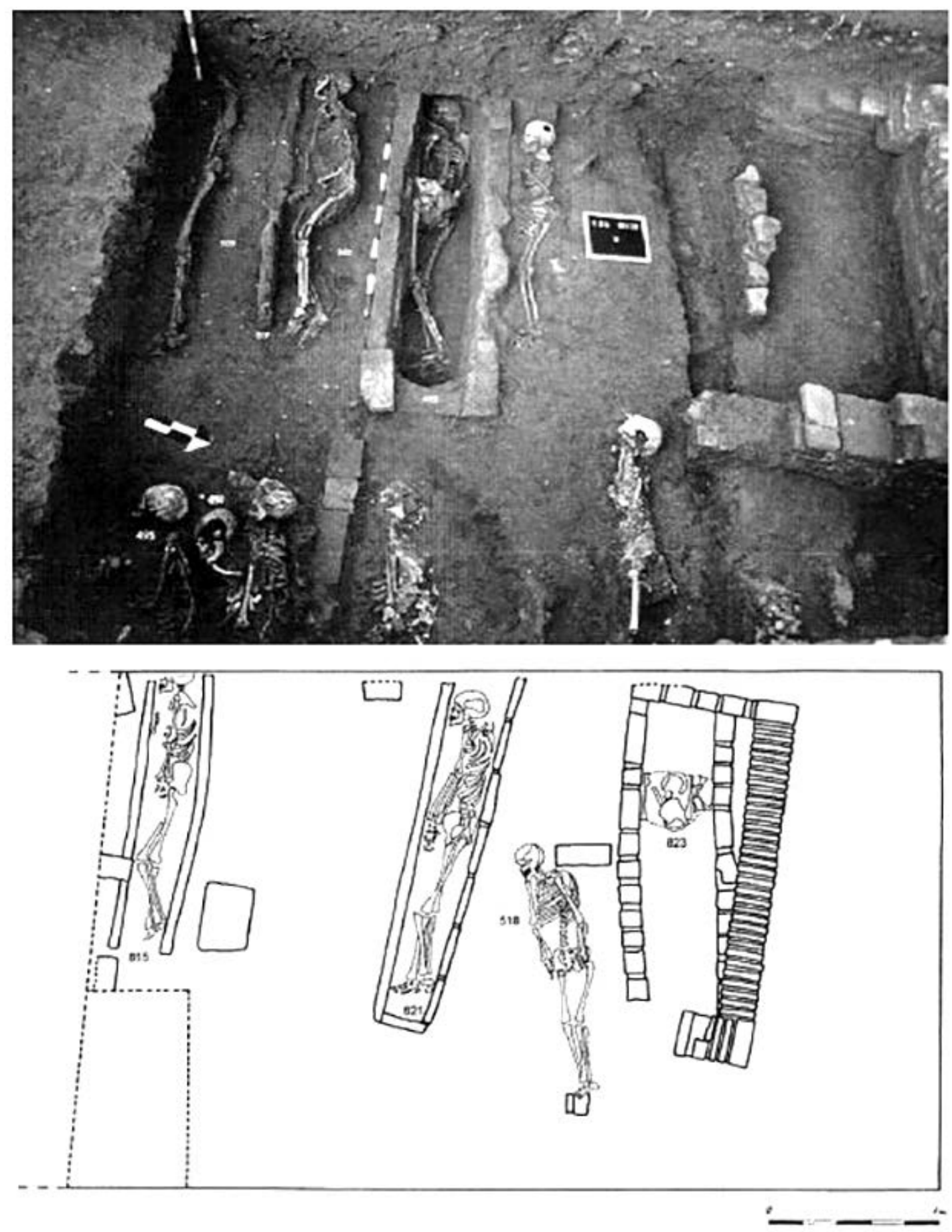

Enterramientos de la makbara de Plaza de España (Vargas y Romo 1998) y (Romo 1998) 
Pasado el tiempo, el otro gran momento de ocupación de El Salón se corresponde ya con época islámica, a partir del $711^{10}$. Se han identificado en las intervenciones arqueológicas vestigios de una enorme necrópolis musulmana (maqbara) en la que han aflorado los restos de más de 4.000 personas, que están siendo objeto de diversos estudios antropológicos que permitirán profundizar en aspectos como la edad de los fallecidos, causas de su muerte, alimentación, etc. Se trata del mayor cementerio andalusí que se ha excavado hasta ahora en la Península Ibérica. Se han recuperado unas 61 inhumaciones a lo largo de ocho fases de estratificación, por lo que hemos de desechar la idea de que se trate de un cementerio espontáneo, surgido a raíz de una epidemia o crisis de mortalidad, puesto que tal densidad funeraria hace suponer que esta necrópolis se mantenga en uso durante un largo periodo de tiempo (Romo 1998).

Los individuos que, gracias a los materiales cerámicos asociados van desde época omeya (VIII) al siglo XIII, se encontraban alineados en dos bandas, aunque hay zonas que nos muestran a algunos más hacinados, detectándose incluso ciertos osarios.

La disposición ritual del difunto es en cubito lateral derecho, con el rostro en dirección sures-

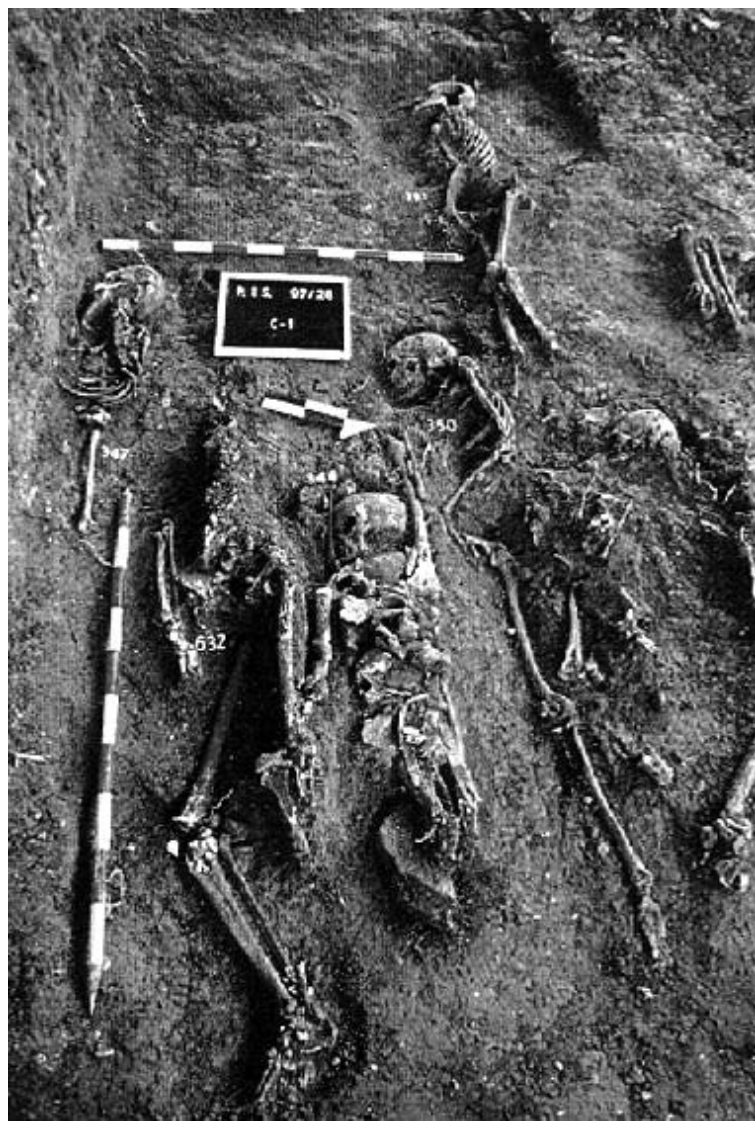
te, muy encajada en las estructuras. Hay 2 ó 3 individuos enterrados en cubito supino, lo que también entraba dentro de lo normal. Responderían por lo tanto al ritual funerario típico islámico con cadáveres orientados hacia la Meca (Romo 1998).

La tipología detectada la encontramos en otros lugares que nos sirven de paralelos. Fosas revestidas con adobes nos las encontramos en Zaragoza desde época Omeya hasta el XII y de aparición más tardía en Murcia y en Valencia (ss. XII - XIII). Fosas con muretes de ladrillos nos las encontramos en Granada (de cronología nazarí) y en Almería (en época taifa-almohade). Cubiertas planas con tejas nos las encontramos en Sevilla, en Valencia capital y en la región valenciana. (ss. XII -XV). Y los paralelos en fosas simples son muy comunes entre los siglo IX al XV.

Es destacable mencionar que hay quienes piensan que el encontrarse cementerios en el interior de las urbes suponía una utilización del espacio para uso funerario desde periodos anteriores a la conquista islámica, como sería

Enterramientos de la makbara de la Plaza de España (Vargas y Romo, 1998)

10.- Hay que señalar como, tras el estudio de las relaciones estratigráficas, podemos afirmar que hubo un claro contacto entre las fases iniciales y las estructuras romanas (Romo 1998). Por otra parte las pavimentaciones de la plaza moderna sellaron literalmente las últimas manifestaciones del cementerio islámico. 
el caso de El Salón. Aunque, como decíamos, también hay muchos casos en los que se habla de que hubo fundaciones de cementerios intramuros en época islámica andalusí como sería el caso de la necrópolis de San Nicolás de Murcia (Navarro y Jiménez 2003), ya que se ven restos humanos sobre restos de antiguas zonas de habitación. No se puede pensar que estos fuesen los únicos casos de cementerios intramuros en el mundo islámico, ya que en el norte de África nos encontramos con otros y en Almería nos encontramos con una necrópolis que se quedó inserta dentro del ámbito urbano con la expansión de la ciudad. L'Almonía en Valencia es otro ejemplo de necrópolis intramuros con muchos elementos similares a la maqbara de El Salón como sería la disposición de los cadáveres y su número. Es reseñable que los musulmanes tenían una conciencia de los espacios funerarios menos rígida que el mundo judeocristiano, ya que no les importaban comerciar o edificar en estos jardines, movidos por el consejo coránico (Navarro y Jiménez 2003).

Es posible que la utilización de El Salón como uso funerario respondiese a un aumento importante de la demografía de la localidad. La variada y numerosa población detectada, así como su extensión y su densidad, nos sirven para descartar organizaciones funerarias como rawdas o qubas (Romo, 1998). Sin embargo, es preciso señalar que en época andalusí se detectan espacios habitacionales abandonados ya desde la tardoantiguedad y que posteriormente quedarían marginados del nuevo cerco de la ciudad por lo que resulta extraño realizar hipótesis basadas en la falta de espacio. Básicamente podría tratarse de un simple aprovechamiento de esta zona, que ya anteriormente sirvió como cementerio en época visigoda (García-Dils, 2009) y que estaría asociado a una mezquita próxima, quizás ubicada en la actual iglesia de San Francisco y que junto a unos posibles baños podría construir lo que se conoce como una fundación piadosa.

\section{LAS MURALLAS DE ÉcIJA}

Para conocer cómo ha evolucionado el urbanismo de Écija hemos visto que debemos partir de la herencia romana. Esta afirmación se basa en el hecho de que la ciudad andalusí ha mantenido algunos rasgos generales de la ciudad romana, documentado tanto en algunos cronistas andalusíes, como en excavaciones arqueológicas (Temiño 1990: 613-614, Valencia 1988: 322-323). Sin embargo, esta afirmación (Valor 2007: 151) debe matizarse para el caso de los elementos defensivos de la Istiyya andalusí, al menos para la época en la que tenemos datos de sus estructuras defensivas: a partir de los almohades. Iremos desgranando estos aspectos.

La muralla de Astigi se inserta en un urbanismo ortogonal, con una estructuración de la ciudad en dos calles principales (cardo-decumanus) que desembocan en cuatro puertas. Sin entrar en detalles ${ }^{11}$, podemos resumir el conocimiento de la muralla romana con una afirmación: "es el elemento que menor rastro ha dejado en la configuración urbana" (Temiño 1990: 619), no quedando ningún resto de la misma (Saez et al, 2001: 255). Sobre su configuración, no tenemos información excepto la que nos da Al-Hiyarí y otros autores de una muralla que tenía Écija a la llegada de los árabes a la península, consistente en un doble recinto amurallado, blanco en la parte interior y rojo en la exterior, de gran dureza (Valencia 1988: 323, Saez et al, 2001: 261, nota 1). A pesar de que esta descripción sería de la muralla del siglo VIII, los autores afirman que este recinto sería el romano y que se mantendría hasta la destrucción ${ }^{12}$ en época califal en el 913 como medida de castigo de Abd el Rahman III contra la ciudad por su apoyo al rebelde Ibn Hafsun (Temiño 1990: 619, Saez et al, 2001: 255).

11.- Se ha propuesto un recinto romano de 3.200 metros de perímetro y 78 hectáreas de extensión (Saez et al, 2001: 256).

12. Según Domínguez y Cervera (2005: 204) “Las destrucciones de murallas realizadas al final de la fitna deberían reinterpretarse en el sentido de rupturas o aportillamientos parciales de los lienzos, antes que como arrasamiento sistemático." 


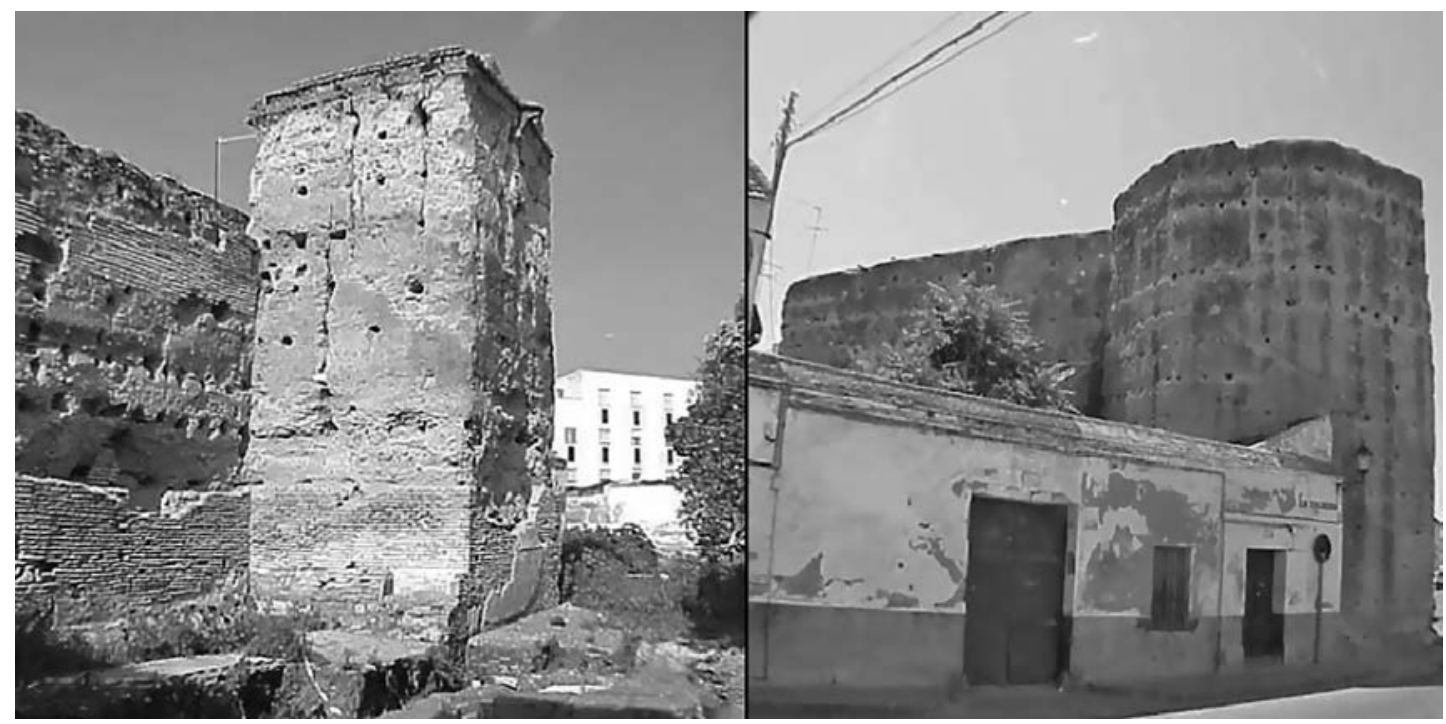

Lienzo y torre de muralla en c/ Cavilla (Sáez et alii, 2004) y la Torre albarrana. Plaza de Colón (Sáez et alii, 2004)

Posteriormente tenemos, además de ciertos datos de una reconstrucción de la misma por Almanzor, la construcción en el siglo XII de una muralla almohade, de la que sí conocemos restos exentos y se ha constatado arqueológicamente. Sin embargo, los trabajos de conjunto sobre la muralla son escasos, teniendo que añadir los resultados obtenidos en las intervenciones arqueológicas publicadas en los AAA. (Valor 2007: 137).

La muralla almohade se construye con un tamaño menor a la romana, ya que corta construcciones romanas (Temiño 1990: 619, Valor 2007: 137): hablamos de un perímetro de 2787 metros con una extensión de 41,7 hectáreas (Saez et al, 2001: 256). La planta tiene tendencia cuadrangular y se caracteriza por tener una forma sinuosa, con siete puertas en recodo. La tipología de la muralla almohade es de lienzos de cajones de tapial, con diversas tipologías de cimientos (mezcla de ladrillos, cantos rodados y tierra con cal, o tapial); y con hiladas de sillares documentadas en la base de algunos tramos de la muralla. Las torres son macizas hasta el adarve y con una cámara abovedada encima (Valor 2007: 137-8), de planta rectangular y distribuidas en tramos regulares. Asociada a la muralla tenemos una barbacana o antemural y foso (Saez et al, 2001), de la que se ha afirmado en varios trabajos cohetaneos de los mismos con la muralla, aunque Valor (2007: 138) duda de que haya evidencias arqueológicas claras al respecto. Dicho antemural tendría un tapial de medidas diferentes al de la muralla, y se ha documentado en la liza un pavimento de mortero de cal. También tenemos que señalar la existencia de torres albarranas de planta poligonal, de las que se conservan cinco, tres de ellas fácilmente observables y dos embutidas en caseríos y casi irreconocibles (Valor 2007: 137-138). Para terminar de ver las estructuras defensivas de la Écija islámica, debemos apuntar la situación del Alcázar (en el entorno del actual picadero), compuesto por dos recintos, el interior cuadrangular de época almohade, en una zona con construcciones arquitectónicas desde el siglo VII-VI a.C. (Saez et al, 2001: 260-261, Valor 2007: 138-139). En total se han estudiado y catalogado 53 lienzos, así como 37 torres y 14 puertas (Saez et al, 2001), aunque sólo siete son de época islámica (Valor 2007: 138). Con este panorama se vuelve a insistir en la reducción del recinto almohade respecto del romano, hecho que sería causado, a tenor de varios autores, por la crisis poblacional que viviría el núcleo en época islámica (Rodríguez 1993: 374-375, Temiño 1990:218). 


\section{Conclusiones}

La ciudad de Astigi romana sufre una serie de cambios propios del medievo andalusí, con enterramientos interiores como el que vemos en la Plaza de España de Écija, la antigua maqbara, o el cambio del viario. Después de analizar en detalle los distintos aspectos de esta importante urbe andaluza, vemos que la antigua capital conventual mantuvo en el periodo andalusí gran parte de su antiguo prestigio y poder político, así como que las transformaciones que se llevaron a cabo en la Alta y Plena Edad Media son las propias que vemos en cualquier ciudad andalusí del mediodía peninsular y que realmente modifican la ciudad, no rompen con los elementos previos.

\section{Bibliografía}

BENDALA, M.

1980 La antigüedad. Historia de Andalucía, Tomo 1, 79-182. Barcelona. Editorial Planeta.

BORRERO, M.

2005 La economía agraria de Écija de la Edad Media al Renacimiento. VII Congreso de Historia de Écija. Écija, Economía y Sociedad, 7, 291-316. Écija. Ayuntamiento de Écija-Diputación Provincial de Sevilla.

CARRASCO, I.

1991 Informe sobre la excavación de urgencia efectuada en la Barrera de Oñate, s/n. de Écija (Sevilla), Informe en la Delegación de Cultura.

CARRASCO, I. y ROMERO, C.

1993 Excavaciones arqueológicas en c/ Mármoles no 6 y c/ Mármoles esquina a c/ Miguel de Cervantes de Écija (Sevilla), AAA'93. III, 711-724.

CASTEJÓN, R.

1965 Excavaciones en Córdoba para localizar las tumbas de los califas, N.A.H., 7, 229-235.

CRUZ, C.

1998 Excavación arqueológica de urgencia en Avda. Miguel de Cervantes angular c/ Mármoles de Écija (Sevilla), Informe en la Delegación de Cultura.

DOMÍNGUEZ, E. L. y CERVERA, L.

2005 Estructura social del territorio en Istiyya. Écija (ss. XI-XIII). Actas del VII Congreso de Historia Ecija, Economia y Sociedad, 187- 214. Écija. Ayuntamiento de Écija.

DURAN, V. y PADILLA, A.

1990 Evolución del poblamiento antiguo en el término municipal de Écija. Écija. Editorial Gráficas Sol.

Fernández, A.

1995 Historia de la ciudad de Écija. Sevilla. Fundación El Monte.

GARCÍA, M.A.

2004 Actividad arqueológica preventiva en la Cilla del Cabildo, plaza de Puerta Cerrada, número 15, de Écija (Sevilla) AAA'2004.III, 893-902. 
GARCÍA-DILS, S.

2004 Plaza de Armas de Écija: Recuperación de un espacio marginal. II Congreso internacional sobre fortificaciones. Ayuntamiento de Sevilla

2005 La tumba visigoda de Sapatio. Spal.

2009 El urbanismo de la Colonia Augusta Firma. Una visión de conjunto a partir de los resultados de las excavaciones arqueológicas en la Plaza de España. Hispania Antigua.

\section{LEVI-PROVENÇAL, E.}

1938 La Péninsule Ibérique au Moyen Âge d'aprés le Kitâb arrawd al-M'itâr fi Habar al-Aktar d'ibn 'Abd Al-Mun'im Al-Himyarî, Leiden.

MUÑOZ, J.

1997a Informe de la excavación arqueológica de urgencia en c/ Ignacio de Soto no 6-8 de Écija (Sevilla), Informe en el Ayuntamiento de Écija (Sevilla).

1997b Intervención arqueológica de urgencia en c/ Merinos c.v. a c/ Puerta Nueva y c/ Jurado de Écija (Sevilla) 1997. Informe en la Delegación de Cultura.

NAVARRO, J. y JIMENEZ, P.

2003 Sobre la ciudad islámica y su evolución. Ramallo, S. F. (ed.): Estudios de Arqueología dedicados a la profesora Ana María Muñoz Amilibia, 319-381.

NÚÑEZ, E. y RODRÍGUEZ, I.

1987 Excavación de urgencia en c/ Cristo de Confalón s/n. de Écija (Sevilla). AAA'87.III, 626-631. NÚÑEZ, E. y HUECAS, J.M.

1990 Informe de la intervención arqueológica efectuada en la Barrera de Oñate, s/n. de Écija (Sevilla). Informe en la Delegación de Cultura.

PAVÓN, B.

1990 Tratado de arquitectura hispano-musulmana, Madrid.

PINILLA, R.

1997 Aportaciones al estudio de la topografía de Córdoba islámica: almacabras, Qurtuba, 2, 175214.

RODRÍGUEZ, I.

1988 Excavación en c/ Miguel de Cervantes no 3 de Écija (Sevilla). AAA'88. III, 418-423.

1990 Pervivencias de alineaciones de época romana en el tejido urbano actual de Écija (Sevilla). Archeologia medievale, 17, 613-623

1993 Aproximación a la forma urbana islámica de Écija. Actas del III Congreso de Historia de Écija. Écija en la Edad Media y Renacimiento, 371-381. Écija. Ayuntamiento de Écija

RODRÍGUEZ, I. y NÚÑEZ, E. 
ROMO, A.

1998 De las termas a la Mackbara. Anuario Arqueológico Andaluz.

SAEZ, P., ORDOÑEZ, S., García, E., GARCÍA-DILS, S.

2001 La cerca islámica de Écija (Sevilla). Congreso Internacional Fortificaciones en el Entorno del Bajo Guadalquivir, 1. 255-263. Alcalá de Guadaira. Ayuntamiento de Alcalá de Guadaira.

2004 Sáez, P.; Ordóñez, S.; García, E.; García-Dils, S.: “Carta arqueológica municipal”. Écija.1: la ciudad. Junta de andalucía. Consejería de cultura.

SÁEZ, P; ORDÓÑEZ, S.; GARCÍA-DILS, S.

2005 El urbanismo de la colonia augusta firma Astigi: nuevas perspectivas. Mainake, 27, 89-112.

SÁNCHEZ, M.

1980 Apogeo y crísis del estado cordobés. Historia de Andalucía, Tomo 1, 183-355. Barcelona. Editorial Planeta.

SANZ, M.J.

1976 Repartimiento de Écija. Estudio y edición, HID 3. 533-551.

TORRES, L.

1957 Cementerios hispanomusumanes, Al-Andalus XXII, 131-191.

VALOR PIECHOTTA, M.

2007 Algunas ciudades del bajo Guadalquivir entre 1150 y 1260: Carmona, Écija, Niebla y Sevilla. Actas del Congreso Al-Andalus. País de ciudades, 133-175. Diputación de Toledo.

VALENCIA, R.

1988 Los territorios de la cora de Écija en época árabe. Actas del I Congreso sobre Historia de Écija, t. I, 315-335. Sevilla. Ayuntamiento de Écija.

VARGAS, J.M., Romo, A.S., García, M. I.

1993 Aproximación a los modelos de asentamiento en el ámbito sureste de la cora de Écija. Actas del III Congreso de Historia de Écija. Écija en la Edad Media y Renacimiento, 13-40. Écija. Ayuntamiento de Écija.

VARGAS JIMÉNEZ, J. M. y ROMO SALAS, A. S.

1998 Informe de la intervención arqueológica de urgencia en la Plaza de España de Écija (Sevi1la). Fase I. Informe en la Delegación de Cultura.

VIGUERA, M. J.

1994 Andalucía islámica (siglos VIII-XV): Territorio, población y comunicaciones. Actas del II Congreso de Historia en Andalucía, Tomo I Historia Medieval, 11-29. Córdoba. Junta de Andalucía, Consejería de Cultura. 
